Discussion It is reasonable to think that any chance to practice a procedure prior to the final attempt at treatment would be beneficial to the physician and, by extension, the patient. This study shows that replicator practice sessions are feasible as long as the replicator model is a functional and faithful representation of the patient's vasculature. In many cases, the replicator session provided an opportunity to correctly size the endovascular device, and avoid resheathing these devices in the patient's intracranial vasculature during the actual procedure. This has the potential to reduce operative time and lower the risk of complications. But the benefits are not limited to properly sizing implants. Even just a chance to rehearse the maneuvers of a procedure benefit the patient in terms of helping to avoid difficulty during the treatment procedure.

Conclusion Difficult endovascular cases, or cases in which a new technology is being used, benefit from a practice session with an individualized 3D model, created to represent the patient's intracranial vasculature. This holds true only when the $3 \mathrm{D}$ model is a functional and accurate reflection of the individual's anatomy.

Disclosures C. Nickele: None. D. Hoit: 1; C; SIemens. 2; C; Siemens, Medtronic, Sequent. L. Elijovich: 1; C; Siemens, Baptist Clinic Research Institute. 2; C; Stryker, Penumbra, Microvention, Covidien. A. Arthur: 1; C; Penumbra, Sequent, Siemens. 2; C; Medtronic, Microvention, Penumbra, Sequent, Siemens, Stryker.

\section{E-091 TREATMENT OF ANEURYSMS OF THE PERICALLOSAL ARTERY WITH THE PIPELINE EMBOLIZATION DEVICE}

${ }^{1} \mathrm{~K}$ de Macedo Rodrigues, ${ }^{1} \mathrm{~A}$ Kühn, ${ }^{1} \mathrm{~T}$ Tamura, ${ }^{2} \mathrm{G}$ Dabus, ${ }^{3} \mathrm{P}$ Kan, ${ }^{1} \mathrm{M}$ Marosfoi, ${ }^{1} \mathrm{~J}$ Lozano, ${ }^{1} \mathrm{M}$ Howk, ${ }^{1} \mathrm{M}$ Perras, ${ }^{1} \mathrm{C}$ Brooks, 'D Rex, ${ }^{1} \mathrm{~F}$ Massari, ${ }^{1} \mathrm{M}$ Gounis, ${ }^{1} \mathrm{~A}$ Wakhloo, ${ }^{1}$ A Puri. ${ }^{1}$ Radiology, University of Massachusetts Medical School, Worcester, MA; ${ }^{2}$ Baptist Cardiac and Vascular Institute, Miami, FL; ${ }^{3}$ Neurosurgery, Baylor College of Medicine, Houston, TX

\subsection{6/neurintsurg-2016-012589.163}

Background/objective Pericallosal artery aneurysm treatment is challenging using traditional endovascular techniques due to the small caliber of the parent vessel and distal access. Wide neck and bifurcation aneurysms in this location require manipulation with 2 catheters for balloon assisted or stent assisted coil embolization with increased friction and limited margin for error. We demonstrate the feasibility, efficacy and safety of endovascular treatment of pericallosal artery aneurysm using flow diversion technology.

Methods We performed a retrospective review of our institutional database from July 2013 through July 2015. Five subjects with a pericallosal artery aneurysm that was treated with the Pipeline embolization device (PED) were identified. We evaluated for technical feasibility, presence of procedural complication, angiographic results, and clinical outcome.

Results Successful placement of a single PED across the neck of the aneurysm was achieved in all cases. No procedurerelated complications were encountered. A 6 month follow-up angiogram was available for 4 patients and a 12 month follow-up angiogram was available for 2 patients. Four out of 5 patients had complete aneurysm occlusion demonstrated, 3 of them were demonstrated at the 6 month follow-up and 1 at 12 month follow-up. The subject for which occlusion was demonstrated at the 12 month follow-up did not have a 6 month angiogram available for review. One patient had persistent aneurysm filling at 6 month, with a 50-60\% decrease in aneurysm size. There were 2 cases of narrowing of at the origin of an artery that had been coved by the PED, without flow limitation or clinical consequences. There was no evidence of in-stent stenosis or intimal hyperplasia. No thromboembolic or hemorrhagic complication was seen. Modified Rankin scale scores remained unchanged from baseline.

Conclusions Our preliminary results support the use of flow diverter stent for treatment of aneurysms of the pericallosal artery with high rate of aneurysm occlusion, without evidence of increased procedural complication or short-term morbidity. A long-term and larger cohort study is desirable to validate our results.

Disclosures K. de Macedo Rodrigues: None. A. Kühn: None. T. Tamura: None. G. Dabus: None. P. Kan: 2; C; PK is a consultant for Stryker Neurovascular, Covidien, and MicroVention.. M. Marosfoi: None. J. Lozano: None. M. Howk: None. M. Perras: None. C. Brooks: None. D. Rex: None. F. Massari: None. M. Gounis: 1; C; NIH, Medtronic Neurovascular, Microvention/Terumo, Cerevasc LLC, Gentuity, Codman Neurovascular, Philips Healthcare, Stryker Neurovascular, Tay Sachs Foundation, and InNeuroCo Inc.. 2; C; Codman Neurovascular and Stryker Neurovascular. 4; C; InNeuroCo Inc. A. Wakhloo: 1; C; NIH, Philips Healthcare, Wyss Institute. 2; C; Codman Neurovascular and Stryker Neurovascular. 4; C; cofounder of InNeuroCo Inc. and major stockholder; stocks in EpiEB and Pulsar Medical. 6; C; speaker: Harvard Postgraduate Course, Miami Cardiovascular Institute. A. Puri: 1; C; Stryker Neurovascular and Covidien. 2; C; Codman Neurovascular, Stryker Neurovascular and Covidien. 4; C; InNeuroCo Inc. 6; C; speaker: Miami Cardiovascular Institute.

\section{E-092 COIL EMBOLIZATION OF INDIRECT CAROTID- CAVERNOUS FISTULA: THE ROLE OF DYNACT IN PRE- TREATMENT PLANNING}

${ }^{1}$ A Botsford, ${ }^{2} \mathrm{~J}$ Shiva Shankar. 'Diagnostic Radiology, Dalhousie University, Halifax, NS, Canada; ${ }^{2}$ Division of Neuroradiology, Dalhousie University, Halifax, NS, Canada

\subsection{6/neurintsurg-2016-012589.164}

Introduction/purpose Indirect Carotid-Cavernous Fistulas (CCF) are arterio-venous shunts between branches of the ICA, ECA or both and the cavernous sinus. Indirect CCFs are treated with coil embolization when they present with orbital/visual symptoms or if there is cortical venous reflux. The target for endovascular treatment in indirect CCF is the occlusion of the venous side of the fistula. Due to intricate anatomy of the cavernous sinus, the fistula site and foot of the draining venous structure are difficult to localize with confidence. This makes treatment a complex and long procedure requiring a large number of coils. Most of the time the treatment is done without actually localizing the fistula site and by packing the whole cavernous sinus with coils, sometimes resulting in additional complications, long procedure times and a large number of coils used per procedure.

The purpose of this study was to examine the role of DynaCT in pre-treatment localization of the fistula site for indirect CCF, and to examine if identification of fistula site would improve treatment by shortening the procedure time, requiring fewer coils or by reducing complication rate. 


\begin{tabular}{|c|c|c|c|c|c|c|c|c|c|c|}
\hline $\begin{array}{l}\text { Patient } \\
\text { No }\end{array}$ & $\begin{array}{l}\text { Dyna } \\
\text { CT } \\
\text { used? }\end{array}$ & $\begin{array}{l}\text { \#Coils } \\
\text { used }\end{array}$ & $\begin{array}{l}\text { Total } \\
\text { Coil } \\
\text { Length }\end{array}$ & $\begin{array}{l}\text { Total } \\
\text { procedural } \\
\text { time }\end{array}$ & $\begin{array}{l}\text { Immediate Post- } \\
\text { procedure Angiographic } \\
\text { result }\end{array}$ & Complications & $\begin{array}{l}\text { Follow-up } \\
\text { imaging time } \\
\text { (Months) }\end{array}$ & $\begin{array}{l}\text { Follow-up } \\
\text { imaging } \\
\text { findings }\end{array}$ & $\begin{array}{l}\text { Clinical follow-up } \\
\text { time (Months) }\end{array}$ & $\begin{array}{l}\text { Resolution of } \\
\text { symptoms at follow- } \\
\text { up? }\end{array}$ \\
\hline 1 & $\mathrm{~N}$ & 14 & $198 \mathrm{~cm}$ & $217 \min$ & Complete occlusion & None & 28 & $\begin{array}{l}\text { No residual } \\
\text { fistula (CT) }\end{array}$ & 57 & Yes \\
\hline 2 & $\mathrm{Y}$ & 8 & $98 \mathrm{~cm}$ & $125 \mathrm{~cm}$ & Complete Occlusion & None & 16 & $\begin{array}{l}\text { No residual } \\
\text { fistula (MRA) }\end{array}$ & 21 & Yes \\
\hline 3 & N & 8 & $180 \mathrm{~cm}$ & $287 \mathrm{~cm}$ & Residual Fistula & None & 5 & $\begin{array}{l}\text { No residual } \\
\text { fistula (MRA) }\end{array}$ & 42 & Yes \\
\hline 4 & $\mathrm{~N}$ & 14 & $192 \mathrm{~cm}$ & $337 \mathrm{~cm}$ & Complete Occlusion & $\begin{array}{l}\text { Yes (headache, } \\
\text { nausea, diplopia) }\end{array}$ & 23 & $\begin{array}{l}\text { No residual } \\
\text { fistula } \\
\text { (MRA) }\end{array}$ & 55 & Yes \\
\hline 5 & Y & 6 & $98 \mathrm{~cm}$ & $412 \mathrm{~cm}$ & $\begin{array}{l}\text { Minimal, slow residual } \\
\text { filling }\end{array}$ & None & 7 & $\begin{array}{l}\text { Small residual } \\
\text { fistula }\end{array}$ & 15 & Yes \\
\hline 6 & Y & 12 & $243 \mathrm{~cm}$ & $215 \mathrm{~cm}$ & $\begin{array}{l}\text { Small residual fistula (no } \\
\text { anterior venous drainage) }\end{array}$ & None & 3 & $\begin{array}{l}\text { No residual } \\
\text { fistula }\end{array}$ & 35 & Yes \\
\hline 7 & Y & 19 & $232 \mathrm{~cm}$ & $213 \mathrm{~cm}$ & Complete Occlusion & None & 6 & $\begin{array}{l}\text { No residual } \\
\text { fistula }\end{array}$ & 20 & No (Resolving) \\
\hline 8 & $\mathrm{Y}$ & 7 & $111 \mathrm{~cm}$ & $81 \mathrm{~cm}$ & Complete Occlusion & None & 15 & $\begin{array}{l}\text { No residual } \\
\text { fistula }\end{array}$ & 26 & Yes \\
\hline
\end{tabular}

Methods Patients with endovascular treatment of indirect CCF between 2005-2015 were retrospectively identified and reviewed from our institutional database. The patients were assessed to see if DynaCT was used in the planning of treatment to identify the site of fistula. All patients were divided into two groups- those who had DynaCT used for treatment planning and those who did not. These two groups were further compared in a retrospective cohort study.

Results A total of 8 patients with 9 fistula sites were included, with a mean age of 52.3 years (range 40-67 years). The majority of the fistulas were Barrow Type D (75\%), and $62.5 \%$ of cases also had cortical venous reflux. DynaCT was used in $5 / 8(62.5 \%)$ patients. Transfemoral venous access to the fistula itself was possible in $7 / 8$ patients $(87.5 \%)$. One patient required direct surgical access via ophthalmic vein cut down. 7/8 patients reported resolution of symptoms at clinical follow-up $(87.5 \%)$.

Mean total coil length was significantly shorter for the group who had DynaCT than for the group who did not $(156.4 \mathrm{~cm}$, vs. $190 \mathrm{~cm}, \mathrm{p}=0.035)$. Mean procedural time was 209 minutes for the DynaCT group vs. 280 minutes for the Non-DynaCT group ( $\mathrm{p}=0.12$ ). A transient neurological complication was seen in only one of the patients.

Conclusion The use of DynaCT in pre-procedural planning allows identification of fistula site for indirect CCF and facilitates selective coil embolization of the foot of the vein. This results in the use of significantly shorter total coil length.

Disclosures A. Botsford: None. J. Shiva Shankar: None.

\section{E-093 CONTRAINDICATIONS FOR RADIAL ACCESS IN ENDOVASCULAR THERAPY OF ACUTE ISCHEMIC STROKES}

K Sivakumar, S Feuenwerker, A Tiwari, D Turkel-Parrella, K Arcot, J Farkas. NYU Lutheran Medical Center, Brooklyn, NY

10.1136/neurintsurg-2016-012589.165
Introduction Alternatives to transfemoral access for acute mechanical thrombectomy have been reported and include direct carotid puncture, brachial artery access, and transradial access. This experience is typically based on a rescue scenario where a transfemoral approach is not feasible or has resulted in failure. Large trials have shown the safety of transradial access for coronary intervention with improved morbidity and mortality rates when compared to transfemoral access for cardiology procedures. When considering an alternative access for difficult interventional stroke therapies a primary consideration for using transradial access should be deliberated. This modality has been adapted for ischemic stroke intervention at several centers including our own. However effective, there are instances in which this modality is ineffective or proves difficult to succeed and should be approached with careful consideration.

Methods All patients seeking endovascular therapy secondary to large vessel occlusions and treated by means of radial artery puncture at our center with documented reperfusion outcome were retrospectively reviewed for analysis. In brief, initial consideration for radial approach requires an assessment of coronary vessel tortuosity through CTA. If qualified, a modified Allen's test is thus performed to determine vascularity and eligibility for radial access. Following artery puncture, a microwire is advanced in adjunct to a 6-7 F sheath, typically a Neuron MAX 088. In cases involving severe aortic arch, a CLARET technique is used, employing the aortic arch and valve to form a loop allowing for access into the more distal neuroanatomy. Once the thrombus is visualized, thrombectomy is carried out in the usual fashion. We identify cases wherein transradial access was employed, either as initial or secondary intentions, with unsuccessful clot engagement.

Results A total of 32 patients met criteria in a retrospective review of our database. Reperfusion to mTICI $2 \mathrm{~b} / 3$ was achieved in $78.1 \%(25 / 32)$ of cases. Of the 7 cases unsuccessfully treated through radial access; difficulties in revascularization as specifically relating to this modality were observed in 4 cases. Radial puncture was not attempted in 2 cases due to 